\title{
BOUNDS ON MODIFIED STOP-LOSS PREMIUMS \\ IN CASE OF KNOWN MEAN AND \\ VARIANCE OF THE RISK VARIABLE
}

By F. De Vylder, M. Goovaerts and N. De Pril

U.C. Louvain and K.U. Leuven, Belgium

\begin{abstract}
In case of a stop-loss treaty the reinsurer takes over that part of the risk that exceeds a given amount $y_{1}$. We will deduce bounds on a modified stop-loss treaty where the liability of the reinsurer is limited to $y_{2}-y_{1}$ in case the claim amount exceeds $y_{2}$. Upper and lower bounds of this modified stop-loss premium are obtained as a simple application of results obtained earlier by the first author.
\end{abstract}

\section{INTRODUCTION}

In case of a stop-loss treaty the insurer takes over that part of the risk that exceeds a given amount $y_{1}$. We now suppose that the stop-loss treaty is modified in such a way that the liability of the reinsurer is limited to $y_{2}-y_{1}$ in case the claim amount exceeds the amount $y_{2}$. Hence, the risk of the reinsurer can be cast into the form

$$
Y= \begin{cases}0 & X \leqslant y_{1} \\ X-y_{1} & y_{1}<X \leqslant y_{2} \\ y_{2}-y_{1} & y_{2}<X .\end{cases}
$$

The net premium then equals:

$$
E(Y)=\int_{y_{1}}^{y_{2}}\left(x-y_{1}\right) d F_{X}(x)+\left(y_{2}-y_{1}\right) \int_{y_{2}}^{\infty} d F_{X}(x)
$$

which can still be cast into the following form:

$$
E(Y)=\int_{a}^{b} \max \left\{\min \left(x-y_{1}, y_{2}-y_{1}\right), 0\right\} d F_{X}(x)
$$

where $y_{2} \geqslant y_{1}, F_{X}(a)=0, F_{X}(b)=1$.

Let $\psi(x)=\max \left\{\min \left(x-y_{1}, y_{2}-y_{1}\right), 0\right\}$, then with $y_{1}, y_{2}, m, m_{2}$ real numbers, we have to consider the following primal problems:

$$
\begin{aligned}
& p_{1}\left(m, m_{2} ; y_{1}, y_{2}\right) \\
& \quad=\sup \left(\int_{a}^{b} \psi(x) d F(x) \mid \int_{a}^{b} x d F(x)=m, \int_{a}^{b} x^{2} d F(x)=m_{2}, \int_{a}^{b} d F(x)=1\right)
\end{aligned}
$$

ASTIN BULLETIN Vol. 13, No. 1 


$$
\begin{aligned}
& q_{1}\left(m, m_{2} ; y_{1}, y_{2}\right) \\
& \quad=\inf \left(\int_{a}^{b} \psi(x) d F(x) \mid \int_{a}^{b} x d F(x)=m, \int_{a}^{b} x^{2} d F(x)=m_{2}, \int_{a}^{b} d F(x)=1\right)
\end{aligned}
$$

where the supremum (infimum) is taken over the distributions $F$ on $[a, b]$ satisfying the constraints indicated after the slash.

We remark that in case $y_{1}<a$ or $y_{2}>b$ the solution of the problem at hand coincides with the solution obtained in DE VYLDER and GoOVAERTS (1982a). This paper contains the basis for our present analysis and the same notation will be used.

Let us first consider the case $y_{1}<a$. We have:

$$
\int_{a}^{b} \psi(x) d F(x)=m-y_{1}-\int_{y_{2}}^{b}\left(x-y_{2}\right) d F(x) .
$$

Consequently:

$$
\sup \int_{a}^{b} \psi(x) d F(x)=m-y_{1}-\inf \int_{y_{2}}^{b}\left(x-y_{2}\right) d F(x)
$$

Hence:

$$
p_{1}\left(m, m_{2} ; y_{1}, y_{2}\right)=m-y_{1}-q_{1}\left(m, m_{2}\right)
$$

and

$$
q_{1}\left(m, m_{2} ; y_{1}, y_{2}\right)=m-y_{1}-p_{1}\left(m, m_{2}\right)
$$

where $q_{1}\left(m, m_{2}\right)$ and $p_{1}\left(m, m_{2}\right)$ are the values of the corresponding problems in DE VYLDER and GoOVAERTS $(1982 a)$, with $e$ changed in $y_{2}$.

In case $y_{2}>b$, on the other hand, we get:

$$
\int_{a}^{b} \psi(x) d F(x)=\int_{y_{1}}^{b}\left(x-y_{1}\right) d F(x)
$$

such that:

$$
p_{1}\left(m, m_{2} ; y_{1}, y_{2}\right)=p_{1}\left(m, m_{2}\right)
$$

and

$$
q_{1}\left(m, m_{2} ; y_{1}, y_{2}\right)=q_{1}\left(m, m_{2}\right)
$$

where $p_{1}\left(m, m_{2}\right)$ and $q_{1}\left(m, m_{2}\right)$ are the values of the corresponding problems in the cited reference, with $e$ changed in $y_{1}$. Consequently, without loss of generality we can restrict ourselves to values $y_{1}, y_{2}$ such that:

$$
a<y_{1}<y_{2}<b \text {. }
$$

The distribution $F$ for which the supremum and infimum are obtained are 3-atomic at most, see e.g., DE VYLDER (1982). If $\alpha$ and $\beta$ are two different atoms of the 2-atomic probability distribution $F$ satisfying the first-order moment 
constraint $\int x d F=m$, then the corresponding probability masses $p_{\alpha}, p_{\beta}$ must necessarily be:

$$
p_{\alpha}=\frac{m-\beta}{\alpha-\beta}, \quad p_{\beta}=\frac{m-\alpha}{\beta-\alpha} .
$$

If $\alpha, \beta, \gamma$ are different atoms of the 3-atomic probability distribution $F$, satisfying the moment constraints $\int x d F=m, \int x^{2} d F=m_{2}$, then the corresponding probability masses can only be:

$p_{\alpha}=\frac{s^{2}+(m-\beta)(m-\gamma)}{(\alpha-\beta)(\alpha-\gamma)}, \quad p_{\beta}=\frac{s^{2}+(m-\alpha)(m-\gamma)}{(\beta-\alpha)(\beta-\gamma)}, \quad p_{\gamma}=\frac{s^{2}+(m-\alpha)(m-\beta)}{(\gamma-\alpha)(\gamma-\beta)}$.

The domain of the parameters $m$ and $m_{2}=s^{2}+m^{2}$ is defined as:

$$
C^{\prime}=\left\{\left(m, m_{2}\right) \mid a \leqslant m \leqslant b, 0 \leqslant s^{2} \leqslant(m-a)(b-m)\right\} .
$$

\section{DEMONSTRATION OF THE MAIN RESULT}

\section{Theorem}

For $\left(m, m_{2}\right)$ belonging to the domain $C^{\prime}$, defined above, the problems $p_{1}\left(m, m_{2} ; y_{1}, y_{2}\right)$ and $q_{1}\left(m, m_{2} ; y_{1}, y_{2}\right)$ with $a<y_{1}<y_{2}<b$ have the value and solution indicated in Table 1 and Table 2 at the end of this note.

\section{Demonstration}

Let $E$ be the curve with parametric equations:

$$
X=x, \quad Y=x^{2}, \quad Z=\max \left\{\min \left(x-y_{1}, y_{2}-y_{1}\right), 0\right\}, \quad a \leqslant x \leqslant b .
$$

The curve $E$ is shown in fig. 1 . She consists of three parts $E_{1}, E_{2}, E_{3}$. The parametric representation in each of the three indicated regions is the following:

$$
\begin{array}{lllll}
E_{1} & X=x & Y=x^{2} & Z=0 & a \leqslant x \leqslant y_{1} \\
E_{2} & X=x & Y=x^{2} & Z=x-y_{1} & y_{1} \leqslant x \leqslant y_{2} \\
E_{3} & X=x & Y=x^{2} & Z=y_{2}-y_{1} & y_{2} \leqslant x \leqslant b .
\end{array}
$$

As far as the problem $p_{1}\left(m, m_{2} ; y_{1}, y_{2}\right)$ is concerned we get immediately three domains, namely $D_{1}, D_{2}, D_{3}$. We successively obtain:

$$
\begin{array}{r}
D_{1}=\left\{\left(m, s^{2}\right) \mid 1\right) a \leqslant m \leqslant y_{2},(m-a)\left(y_{2}-m\right) \leqslant s^{2} \leqslant(m-a)(b-m) \\
\text { 2) } \left.y_{2} \leqslant m \leqslant b,\left(m-y_{2}\right)(b-m) \leqslant s^{2} \leqslant(m-a)(b-m)\right\} .
\end{array}
$$

The equation of the plane through the three points $A, P_{2}$ and $B$ enables us to construct an upper bound or a solution of the problem $p_{1}\left(m, m_{2} ; y_{1}, y_{2}\right)$ in $D_{1}$ :

$$
Z=\left(y_{2}-y_{1}\right) \frac{Y-\left(y_{2}+b\right) X+a\left(y_{2}+b-a\right)}{(a-b)\left(y_{2}-a\right)} \text {. }
$$


Consequently in $D_{1}$ :

$$
p_{1}\left(m, m_{2} ; y_{1}, y_{2}\right)=\left(y_{2}-y_{1}\right) \frac{(m-a)\left(b+y_{2}-m-a\right)-s^{2}}{(b-a)\left(y_{2}-a\right)}
$$

$$
D_{2}=\left\{\left(m, s^{2}\right) \mid y_{2} \leqslant m \leqslant b, 0 \leqslant s^{2} \leqslant\left(m-y_{2}\right)(b-m)\right\} \text {. }
$$

In this case it is readily seen that:

$$
\begin{gathered}
p_{1}\left(m, m_{2} ; y_{1}, y_{2}\right)=y_{2}-y_{1} \\
D_{3}=\left\{\left(m, s^{2}\right) \mid a \leqslant m \leqslant y_{2}, 0 \leqslant s^{2} \leqslant(m-a)\left(y_{2}-m\right)\right\} .
\end{gathered}
$$

We consider a point $Q_{1}$ on $E_{1}$ with coordinates $\left(x, x^{2}, 0\right)$ and a point $Q_{2}$ on $E_{2}$ with coordinates $\left(y, y^{2}, y-y_{1}\right)$ and determine the equation of the plane through $Q_{1}$ and $Q_{2}$, tangent on $E_{1}$ in $Q_{1}$ and tangent on $E_{2}$ in $Q_{2}$. The equation reads:

$$
Z=z_{1} X+z_{2} Y+z_{3}
$$

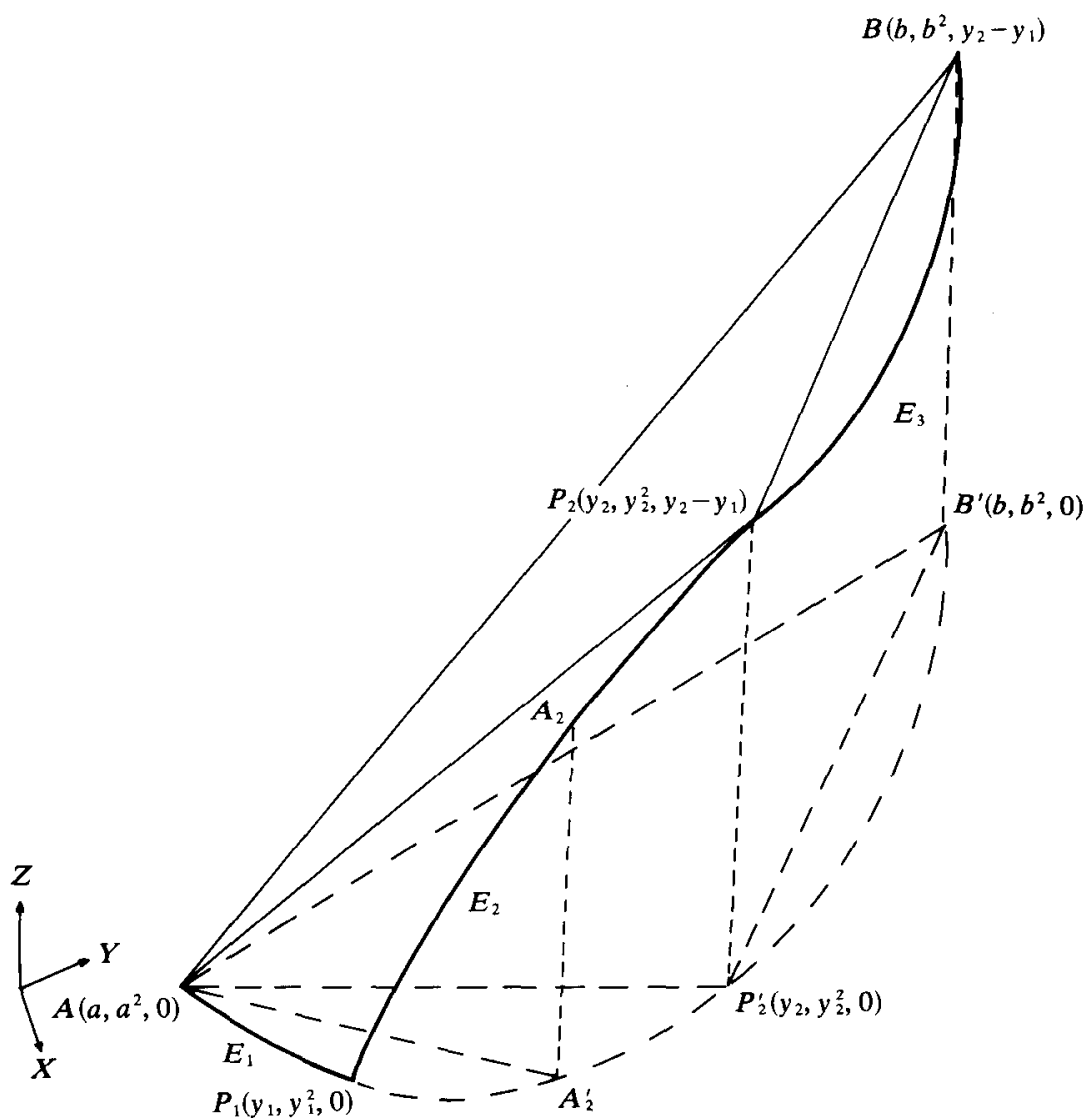

Figure 1. Curve E. 
with:

$$
\begin{aligned}
0 & =z_{1} x+z_{2} x^{2}+z_{3} & & Q_{1} \in \text { plane } \\
y-y_{1} & =z_{1} y+z_{2} y^{2}+z_{3} & & Q_{2} \in \text { plane } \\
1 & =z_{1}+2 z_{2} y & & \text { tangent in } Q_{2} \\
0 & =z_{1}+2 z_{2} x & & \text { tangent in } Q_{1} .
\end{aligned}
$$

Solving the first three equations of this system of equations with respect to $z_{1}$, $z_{2}, z_{3}$ gives:

$$
z_{2}=\frac{y_{1}-x}{(x-y)^{2}}, \quad z_{1}=\frac{x^{2}+y^{2}-2 y y_{1}}{(x-y)^{2}}
$$

Of course $z_{1}, z_{2}$ still need to satisfy the last equation. This gives:

$$
(y-x)\left(y+x-2 y_{1}\right)=0 \text {. }
$$

Hence with $Q_{1}\left(x, x^{2}, 0\right)$ on $E_{1}$ corresponds the point $Q_{2}\left(2 y_{1}-x,\left(2 y_{1}-x\right)^{2}, y_{1}-x\right)$ on $E_{2}$.

Now we have to consider two cases according to the position of the point $A_{2}\left(2 y_{1}-a,\left(2 y_{1}-a\right)^{2}, y_{1}-a\right)$ corresponding to $A\left(a, a^{2}, 0\right)$.

In case $y_{1}-a \leqslant y_{2}-y_{1}, A_{2}$ is lying under $P_{2}$, and we can consider a partition of $D_{3}$ in $D_{31}$ and $D_{32}$.

In case $y_{1}-a \geqslant y_{2}-y_{1}$ the point $A_{1}$ on $E_{1}$ corresponding with $P_{2}$ is lying to the right of $A$ and we have to consider a partition $D_{31}^{\prime}$ and $D_{32}^{\prime}$ as in fig. 3 .

Let us examine now both cases separately.

(i) $2 y_{1}-a \leqslant y_{2}$

$$
D_{31}=\left\{\left(m, s^{2}\right) \mid a<m \leqslant 2 y_{1}-a, 0 \leqslant s^{2} \leqslant\left(2 y_{1}-a-m\right)(m-a)\right\} .
$$

The equation of the plane through $\left(x, x^{2}, 0\right)$ tangent to $E_{1}$ and also tangent to $E_{2}$ is:

$$
Z=\frac{1}{(x-y)^{2}}\left[\left(x^{2}+y^{2}-2 y y_{1}\right)(X-x)+\left(y_{1}-x\right)\left(Y-x^{2}\right)\right]
$$

of course with $y=2 y_{1}-x$, or:

$$
Z=\frac{1}{4\left(y_{1}-x\right)}\left(-2 x X+Y+x^{2}\right)
$$

Hence the equation of the envelope of this set of planes reads:

$$
4\left(y_{1}-X+2 Z\right) Z=-2(X-2 Z) X+Y+(X-2 Z)^{2} .
$$




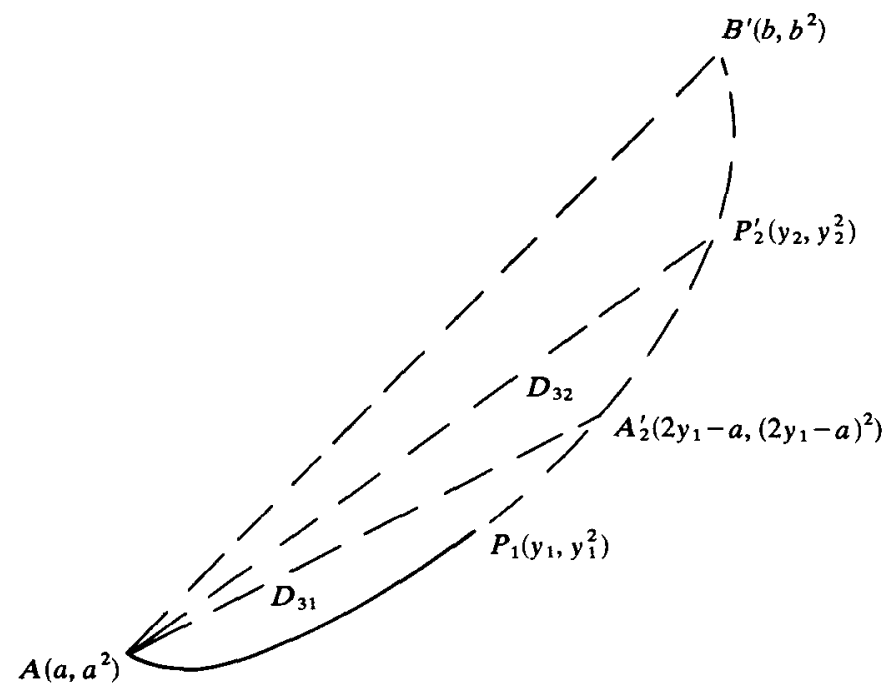

Figure 2. Partition of $D_{3}$ in case $2 y_{1}-a \leqslant y_{2}$.

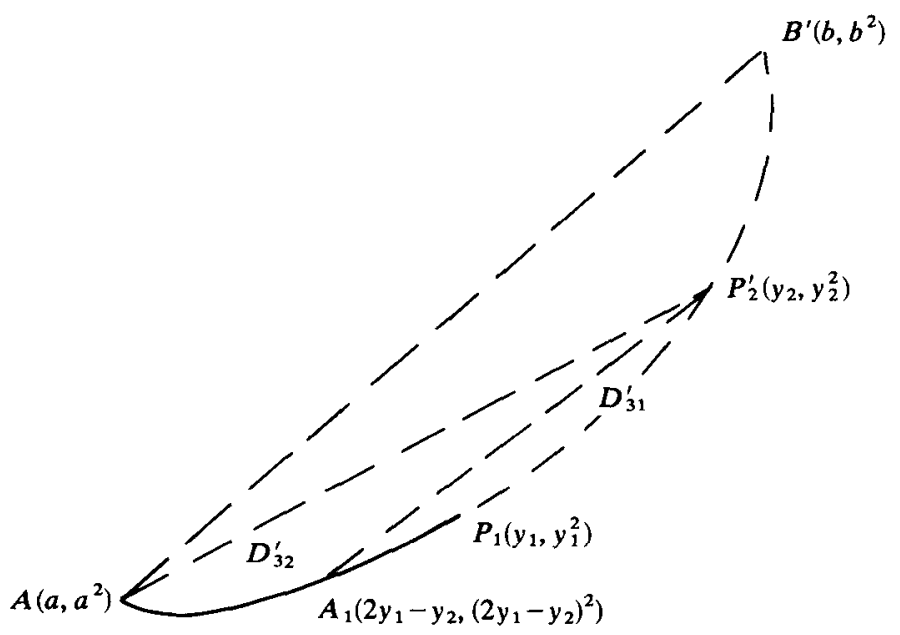

FIGURE 3. Partition of $D_{3}$ in case $2 y_{1}-a \geqslant y_{2}$.

\section{Consequently:}

$$
p_{1}\left(m, m_{2} ; y_{1}, y_{2}\right)=\frac{1}{2}\left(m-y_{1}\right)+\frac{1}{2} s_{m y_{1}}
$$

with

$$
s_{m y_{1}}^{2}=\left(y_{1}-m\right)^{2}+s^{2} .
$$


Let us consider now:

$$
\begin{gathered}
D_{32}=\left\{\left(m, s^{2}\right) \mid 1\right) a \leqslant m \leqslant 2 y_{1}-a,(m-a)\left(2 y_{1}-a-m\right) \leqslant s^{2} \leqslant(m-a)\left(y_{2}-m\right) \\
\text { 2) } \left.2 y_{1}-a \leqslant m \leqslant y_{2}, 0 \leqslant s^{2} \leqslant(m-a)\left(y_{2}-m\right)\right\} .
\end{gathered}
$$

The equation of the plane through $A\left(a, a^{2}, 0\right)$ and through $Q_{2}$ and tangent on $E_{2}$ in $Q_{2}$ is obtained by eliminating $z_{1}, z_{2}, z_{3}$ from the following system of equations:

$$
\begin{aligned}
Z & =z_{1} X+z_{2} Y+z_{3} \\
0 & =z_{1} a+z_{2} a^{2}+z_{3} \\
y-y_{1} & =z_{1} y+z_{2} y^{2}+z_{3} \\
1 & =z_{1}+2 z_{2} y .
\end{aligned}
$$

This gives:

$$
(Z-X+a)\left(Y-2 X a+a^{2}\right)+\left(y_{1}-a\right)(X-a)^{2}=0 .
$$

And consequently:

$$
p_{1}\left(m, m_{2} ; y_{1}, y_{2}\right)=m-a-\frac{\left(y_{1}-a\right)(m-a)^{2}}{s^{2}+(m-a)^{2}}
$$

(ii) $2 y_{1}-a \geqslant y_{2}$

The point $A_{1}$ corresponding to $P_{2}$ has the following set of coordinates:

$$
\left(2 y_{1}-y_{2},\left(2 y_{1}-y_{2}\right)^{2}, 0\right) \text {. }
$$

Consequently in:

$$
D_{31}^{\prime}=\left\{\left(m, s^{2}\right) \mid 2 y_{1}-y_{2} \leqslant m \leqslant y_{2}, 0 \leqslant s^{2} \leqslant\left(m-2 y_{1}+y_{2}\right)\left(y_{2}-m\right)\right\}
$$

we obtain the same upper bound as in $D_{31}$.

$$
p_{1}\left(m, m_{2} ; y_{1}, y_{2}\right)=\frac{1}{2}\left(m-y+s_{m y_{1}}\right) \text {. }
$$

Let us consider next:

$$
\begin{aligned}
& D_{32}^{\prime}=\left\{\left(m, s^{2}\right) \mid\right.1) 2 y_{1}-y_{2} \leqslant m \leqslant y_{2},\left(y_{2}-m\right)\left(m-2 y_{1}+y_{2}\right) \leqslant s^{2} \\
& \leqslant(m-a)\left(y_{2}-m\right) \\
&\text { 2) } \left.a \leqslant m \leqslant 2 y_{1}-y_{2}, 0 \leqslant s^{2} \leqslant(m-a)\left(y_{2}-m\right)\right\} .
\end{aligned}
$$

We then have to determine the equation of the plane going through $P_{2}\left(y_{2}, y_{2}^{2}, y_{2}-\right.$ $\left.y_{1}\right)$, through $Q_{1}\left(x, x^{2}, 0\right)$ and tangent on $E_{1}$ in $Q_{1}$. This equation is obtained by eliminating $z_{1}, z_{2}$ and $z_{3}$ from the following system of equations:

$$
\begin{aligned}
Z & =z_{1} X+z_{2} Y+z_{3} \\
y_{2}-y_{1} & =z_{1} y_{2}+z_{2} y_{2}^{2}+z_{3} \\
0 & =z_{1} x+z_{2} x^{2}+z_{3} \\
0 & =z_{1}+2 z_{2} x .
\end{aligned}
$$


This gives:

$$
Z\left(2 y_{2} X-Y-y_{2}^{2}\right)=X^{2}\left(y_{2}-y_{1}\right)-Y\left(y_{2}-y_{1}\right)
$$

and of course:

$$
p_{1}\left(m, m_{2} ; y_{1}, y_{2}\right)=\left(y_{2}-y_{1}\right) \frac{s^{2}}{s^{2}+\left(m-y_{2}\right)^{2}}
$$

As far as the atoms of the extremal distributions are concerned the solution can be obtained, completely similar to the solutions obtained in DE VYLDER and GOOVAERTS $(1982 a)$.

Now we come to the solution of the problem $q_{1}\left(m, m_{2} ; y_{1}, y_{2}\right)$. In this case we have to consider the following three domains.

$$
\begin{array}{r}
D_{4}=\left\{\left(m, s^{2}\right) \mid \text { 1) } a \leqslant m \leqslant y_{1},(m-a)\left(y_{1}-m\right) \leqslant s^{2} \leqslant(m-a)(b-m)\right. \\
\text { 2) } \left.y_{1} \leqslant m \leqslant b,\left(m-y_{1}\right)(b-m) \leqslant s^{2} \leqslant(m-a)(b-m)\right\} .
\end{array}
$$

In order to obtain the solution of the problem $q_{1}\left(m, m_{2} ; y_{1}, y_{2}\right)$ we have to determine the equation of the plane through $A, P_{1}$ and $B$. The equation reads:

$$
Z=\left(y_{2}-y_{1}\right) \frac{Y-\left(y_{1}+a\right) X+a y_{1}}{(b-a)\left(b-y_{1}\right)} \text {. }
$$

Hence:

$$
\begin{gathered}
q_{1}\left(m, m_{2} ; y_{1}, y_{2}\right)=\left(y_{2}-y_{1}\right) \frac{s^{2}+(m-a)\left(m-y_{1}\right)}{(b-a)\left(b-y_{1}\right)} \\
D_{5}=\left\{\left(m, s^{2}\right) \mid a \leqslant m \leqslant y_{1}, 0 \leqslant s^{2} \leqslant(m-a)\left(y_{1}-m\right)\right\} .
\end{gathered}
$$

In this case it is readily seen that:

$$
\begin{gathered}
q_{1}\left(m, m_{2} ; y_{1}, y_{2}\right)=0 \\
D_{6}=\left\{\left(m, s^{2}\right) \mid y_{1} \leqslant m \leqslant b, 0 \leqslant s^{2} \leqslant\left(m-y_{1}\right)(b-m)\right\} .
\end{gathered}
$$

We have to determine the equation of the plane through $Q_{2}\left(y, y^{2}, y-y_{1}\right)$ tangent on $E_{2}$ in $Q_{2}$ and through $Q_{3}\left(z, z^{2}, y_{2}-y_{1}\right)$ tangent on $E_{3}$. The equation of this plane reads:

$$
Z=z_{1} X+z_{2} Y+z_{3}
$$

where:

$$
\begin{aligned}
y-y_{1} & =z_{1} y+z_{2} y^{2}+z_{3} \\
y_{2}-y_{1} & =z_{1} z+z_{2} z^{2}+z_{3} \\
0 & =z_{1}+2 z z_{2} \\
1 & =z_{1}+2 z_{2} y .
\end{aligned}
$$


Solving this equation with respect to $z_{1}$ and $z_{2}$ gives:

$$
z_{2}=\frac{y_{2}-z}{(y-z)^{2}}, \quad z_{1}=\frac{y^{2}+z^{2}-2 y y_{2}}{(y-z)^{2}} .
$$

These solutions have to satisfy $0=z_{1}+2 z z_{2}$, hence:

$$
z=2 y_{2}-y \text {. }
$$

Consequently with the point $Q_{2}\left(y, y^{2}, y-y_{1}\right)$ on $E_{2}$ corresponds the point $Q_{3}\left(2 y_{2}-y,\left(2 y_{2}-y\right)^{2}, y_{2}-y_{1}\right)$ on $E_{3}$. We have to consider two cases, namely $2 y_{2}-y_{1} \leqslant b$ and $2 y_{2}-y_{1} \geqslant b$.

(i) $2 y_{2}-y_{1} \leqslant b$

In the present situation we consider a partition of $D_{6}$ as shown in fig. 4 .

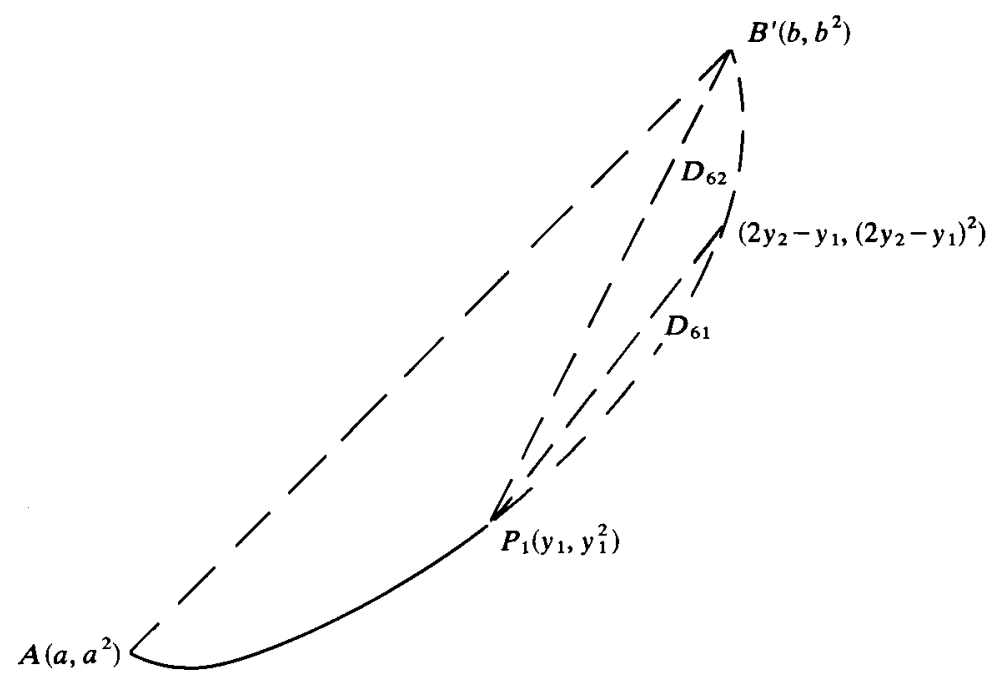

FIGURE 4. Partition of $D_{6}$ in case $2 y_{2}-y_{1} \leqslant b$.

We have:

$$
D_{61}=\left\{\left(m, s^{2}\right) \mid y_{1} \leqslant m \leqslant 2 y_{2}-y_{1}, 0 \leqslant s^{2} \leqslant\left(m-y_{1}\right)\left(2 y_{2}-y_{1}-m\right)\right\} .
$$

Next we have to deduce the equation of the envelope of the set of planes:

$$
Z=y_{2}-y_{1}+\frac{y^{2}+z^{2}-2 y y_{2}}{(y-z)^{2}}(X-z)+\frac{y_{2}-z}{(y-z)^{2}}\left(Y-z^{2}\right)
$$

with $z=2 y_{2}-y$.

Substitution gives:

$$
4\left(y-y_{2}\right)\left(Z-y_{2}+y_{1}\right)=2\left(y-2 y_{2}\right)\left(X-\left(2 y_{2}-y\right)\right)+Y-\left(2 y_{2}-y\right)^{2} .
$$


The equation of the envelope is obtained by eliminating $y$ between this equation and the next one, obtained by taking the derivative with respect to $y$ in the preceeding equation

$$
y=2 Z+2 y_{1}-X
$$

Hence the equation of the envelope becomes:

$$
\left(2 Z+2 y_{1}-X-y_{2}\right)^{2}=\left(y_{2}-X\right)^{2}+Y-X^{2} .
$$

Finally

$$
q_{1}\left(m, m_{2} ; y_{1}, y_{2}\right)=\frac{1}{2}\left(y_{2}+m-2 y_{1}-s_{m y_{2}}\right) .
$$

Next we consider:

$$
\begin{gathered}
D_{62}=\left\{\left(m, s^{2}\right) \mid 1\right) y_{1} \leqslant m \leqslant 2 y_{2}-y_{1},\left(m-y_{1}\right)\left(2 y_{2}-y_{1}-m\right) \leqslant s^{2} \leqslant\left(m-y_{1}\right)(b-m) \\
\text { 2) } \left.2 y_{2}-y_{1} \leqslant m \leqslant b, 0 \leqslant s^{2} \leqslant\left(m-y_{1}\right)(b-m)\right\} .
\end{gathered}
$$

In the present situation the envelope is obtained by considering a set of planes through $\left(y_{1}, y_{1}^{2}, 0\right)$ and tangent on $E_{3}$. We get:

$$
\begin{aligned}
Z & =z_{1} X+z_{2} Y+z_{3} \\
0 & =z_{1} y_{1}+z_{2} y_{1}^{2}+z_{3} \\
y_{2}-y_{1} & =z_{1} z+z_{2} z^{2}+z_{3} \\
0 & =z_{1}+2 z_{2} z .
\end{aligned}
$$

Eliminating $z_{1}, z_{2}$ and $z_{3}$ gives:

$$
Z=2 z \frac{y_{2}-y_{1}}{\left(z-y_{1}\right)^{2}}\left(X-y_{1}\right)-\frac{y_{2}-y_{1}}{\left(z-y_{1}\right)^{2}}\left(Y-y_{1}^{2}\right)
$$

Consequently the envelope of this set of planes depending on $z$ is obtained by eliminating $z$ between this equation and the derivative with respect to $z$.

$$
\left(z-y_{1}\right) Z=\left(y_{2}-y_{1}\right)\left(X-y_{1}\right) \text {. }
$$

This results in

$$
-Z\left(2 y_{1} X-y_{1}^{2}-Y\right)=\left(y_{2}-y_{1}\right)\left(X-y_{1}\right)
$$

Hence

$$
q_{1}\left(m, m_{2} ; y_{1}, y_{2}\right)=\left(y_{2}-y_{1}\right) \frac{\left(m-y_{1}\right)^{2}}{s^{2}+\left(m-y_{1}\right)^{2}}
$$

(ii) $2 y_{2}-y_{1} \geqslant b$

In this case we have to consider a partition of $D_{6}$ in $D_{61}^{\prime}$ and $D_{62}^{\prime}$, as indicated in fig. 5 . 


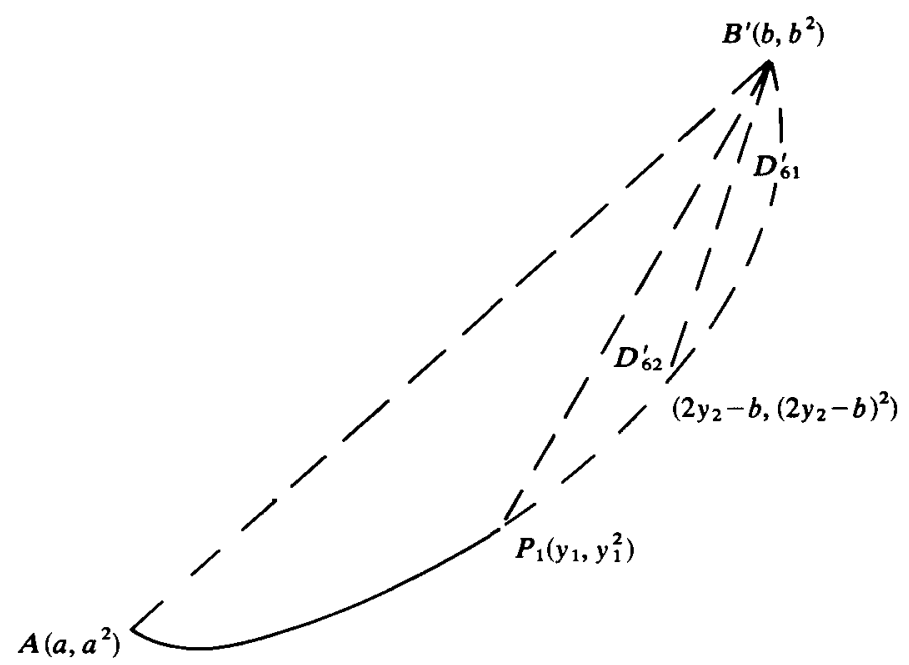

Figure 5. Partition of $D_{6}$ in case $2 y_{2}-y_{1} \geqslant b$.

In the domain

$$
D_{61}^{\prime}=\left\{\left(m, s^{2}\right) \mid 2 y_{2}-b \leqslant m \leqslant b, 0 \leqslant s^{2} \leqslant\left(m-2 y_{2}+b\right)(b-m)\right\}
$$

the same result as in the case $D_{61}$ applies.

Hence

$$
q\left(m, m_{2} ; y_{1}, y_{2}\right)=\frac{1}{2}\left(y_{2}+m-2 y_{1}-s_{m y_{2}}\right) .
$$

On the other hand we have:

$$
\begin{gathered}
D_{62}^{\prime}=\left\{\left(m, s^{2}\right) \mid 1\right) 2 y_{2}-b \leqslant m \leqslant b,\left(m-2 y_{2}+b\right)(b-m) \leqslant s^{2} \leqslant\left(m-y_{1}\right)(b-m) \\
\text { 2) } \left.y_{1} \leqslant m \leqslant 2 y_{2}-b, 0 \leqslant s^{2} \leqslant\left(m-y_{1}\right)(b-m)\right\} .
\end{gathered}
$$

We have to examine the set of planes through $B\left(b, b^{2}, y_{2}-y_{1}\right)$, through a point of $E_{2}$ and tangent on $E_{2}$ in that point.

These planes are determined by the following equations:

$$
\begin{aligned}
Z & =z_{1} X+z_{2} Y+z_{3} \\
y_{2}-y_{1} & =z_{1} b+z_{2} b^{2}+z_{3} \\
y-y_{1} & =z_{1} y+z_{2} y^{2}+z_{3} \\
1 & =z_{1}+2 z_{2} y .
\end{aligned}
$$

Hence the parametric representation of these planes reads:

$$
Z=y_{2}-y_{1}+\frac{y^{2}+b^{2}-2 y y_{2}}{(y-b)^{2}}(X-b)-\frac{b-y_{2}}{(y-b)^{2}}\left(Y-b^{2}\right) \text {. }
$$


Taking the derivative with respect to $y$ gives:

$$
(y-b)\left(Z-y_{2}+y_{1}\right)=\left(y-y_{2}\right)(X-b) .
$$

Hence, the following equation is obtained for the envelope:

such that:

$$
\left(\frac{Y-b^{2}}{X-b}-2 b\right)\left(Z-y_{2}+y_{1}\right)=\left(\frac{Y-b^{2}}{X-b}-b-y_{2}\right)(X-b)
$$

$$
q_{1}\left(m, m_{2} ; y_{1}, y_{2}\right)=y_{2}-y_{1}+\frac{s^{2}+\left(m-y_{2}\right)(m-b)}{s^{2}+(m-b)^{2}}(m-b)
$$

\section{TABLES 1 AND 2}

Value and Solutions of the Primal Problem

\begin{tabular}{|c|c|c|}
\hline $\begin{array}{l}\text { Maximization } \\
\text { Conditions }\end{array}$ & Value of the problem & Atoms \\
\hline $\begin{array}{l}a \leqslant m \leqslant y_{2} \\
(m-a)\left(y_{2}-m\right) \leqslant s^{2} \leqslant(m-a)(b-m)\end{array}$ & $\left(y_{2}-y_{1}\right) \frac{(m-a)\left(b+y_{2}-m-a\right)-s^{2}}{(b-a)\left(y_{2}-a\right)}$ & $a, y_{2}, b$ \\
\hline $\begin{array}{l}y_{2} \leqslant m \leqslant b \\
\left(m-y_{2}\right)(b-m) \leqslant s^{2} \leqslant(m-a)(b-m)\end{array}$ & $\left(y_{2}-y_{1}\right) \frac{(m-a)\left(b+y_{2}-m-a\right)-s^{2}}{(b-a)\left(y_{2}-a\right)}$ & $a, y_{2}, b$ \\
\hline $\begin{array}{l}y_{2} \leqslant m \leqslant b \\
0 \leqslant s^{2} \leqslant\left(m-y_{2}\right)(b-m)\end{array}$ & $y_{2}-y_{1}$ & $y_{2}, m, b$ \\
\hline $\begin{array}{l}a \leqslant m \leqslant y_{2} \\
0 \leqslant s^{2} \leqslant(m-a)\left(y_{2}-m\right)\end{array}$ & & \\
\hline $\begin{array}{l}\text { (i) } 2 y_{1}-a \leqslant y_{2} \\
a \leqslant m \leqslant 2 y_{1}-a \\
0 \leqslant s^{2} \leqslant\left(2 y_{1}-a-m\right)(m-a)\end{array}$ & $\frac{1}{2}\left(m-y_{1}+s_{m y_{1}}\right)$ & $y_{1}-s_{m y_{1}}, y_{1}+s_{m y_{1}}$ \\
\hline $\begin{array}{l}a \leqslant m \leqslant 2 y_{1}-a \\
(m-a)\left(2 y_{1}-a-m\right) \leqslant s^{2} \\
\quad \leqslant(m-a)\left(y_{2}-m\right)\end{array}$ & $m-a-\frac{\left(y_{1}-a\right)(m-a)^{2}}{s^{2}+(m-a)^{2}}$ & $a, m+\frac{s^{2}}{m-a}$ \\
\hline $\begin{array}{l}2 y_{1}-a \leqslant m \leqslant y_{2} \\
0 \leqslant s^{2} \leqslant(m-a)\left(y_{2}-m\right)\end{array}$ & $m-a-\frac{\left(y_{1}-a\right)(m-a)^{2}}{s^{2}+(m-a)^{2}}$ & $a, m+\frac{s^{2}}{m-a}$ \\
\hline $\begin{array}{l}2 y_{1}-y_{2} \leqslant m \leqslant y_{2} \\
0 \leqslant s^{2} \leqslant\left(m-2 y_{1}+y_{2}\right)\left(y_{2}-m\right) \\
\text { (ii) } 2 y_{1}-a \geqslant y_{2}\end{array}$ & $\frac{1}{2}\left(m-y_{1}+s_{m y_{1}}\right)$ & $y_{1}-s_{m y_{1}}, y_{1}+s_{m y_{1}}$ \\
\hline $\begin{array}{l}2 y_{1}-y_{2} \leqslant m \leqslant y_{2} \\
\left(y_{2}-m\right)\left(m-2 y_{1}+y_{2}\right) \leqslant s^{2} \\
\quad \leqslant(m-a)\left(y_{2}-m\right)\end{array}$ & $\left(y_{2}-y_{1}\right) \frac{s^{2}}{s^{2}+\left(m-y_{2}\right)^{2}}$ & $m-\frac{s^{2}}{y_{2}-m}, y_{2}$ \\
\hline $\begin{array}{l}a \leqslant m \leqslant 2 y_{1}-y_{2} \\
0 \leqslant s^{2} \leqslant(m-a)\left(y_{2}-m\right)\end{array}$ & $\left(y_{2}-y_{1}\right) \frac{s^{2}}{s^{2}+\left(m-y_{2}\right)^{2}}$ & $m-\frac{s^{2}}{y_{2}-m}, y_{2}$ \\
\hline
\end{tabular}

Abbreviation: $s_{m y}^{2}=s^{2}+(m-y)^{2}$

Domain of the parameters: $a \leqslant m \leqslant b, 0 \leqslant s^{2} \leqslant(m-a)(b-m)$ 


\begin{tabular}{|c|c|c|}
\hline $\begin{array}{l}a \leqslant m \leqslant y_{1} \\
(m-a)\left(y_{1}-m\right) \leqslant s^{2} \leqslant(m-a)(b-m)\end{array}$ & $\left(y_{2}-y_{1}\right) \frac{s^{2}+(m-a)\left(m-y_{1}\right)}{(b-a)\left(b-y_{1}\right)}$ & $a, y_{1}, b$ \\
\hline $\begin{array}{l}y_{1} \leqslant m \leqslant b \\
\left(m-y_{1}\right)(b-m) \leqslant s^{2} \leqslant(m-a)(b-m)\end{array}$ & $\left(y_{2}-y_{1}\right) \frac{s^{2}+(m-a)\left(m-y_{1}\right)}{(b-a)\left(b-y_{1}\right)}$ & $a, y_{1}, b$ \\
\hline $\begin{array}{l}a \leqslant m \leqslant y_{1} \\
0 \leqslant s^{2} \leqslant(m-a)\left(y_{1}-m\right)\end{array}$ & 0 & $a, m, y_{1}$ \\
\hline $\begin{array}{l}y_{1} \leqslant m \leqslant b \\
0 \leqslant s^{2} \leqslant\left(m-y_{1}\right)(b-m)\end{array}$ & & \\
\hline $\begin{array}{l}\text { (i) } 2 y_{2}-y_{1} \leqslant b \\
y_{1} \leqslant m \leqslant 2 y_{2}-y_{1} \\
0 \leqslant s^{2} \leqslant\left(m-y_{1}\right)\left(2 y_{2}-y_{1}-m\right)\end{array}$ & $\frac{1}{2}\left(y_{2}+m-2 y_{1}-s_{m y_{2}}\right)$ & $y_{2}-s_{m y_{2}}, y_{2}+s_{m y_{2}}$ \\
\hline $\begin{array}{l}y_{1} \leqslant m \leqslant 2 y_{2}-y_{1} \\
\left(m-y_{1}\right)\left(2 y_{2}-y_{1}-m\right) \leqslant s^{2} \\
\quad \leqslant\left(m-y_{1}\right)(b-m)\end{array}$ & $\left(y_{2}-y_{1}\right) \frac{\left(m-y_{1}\right)^{2}}{s^{2}+\left(m-y_{1}\right)^{2}}$ & $y_{1}, m+\frac{s^{2}}{m-y_{1}}$ \\
\hline $\begin{array}{l}2 y_{2}-y_{1} \leqslant m \leqslant b \\
0 \leqslant s^{2} \leqslant\left(m-y_{1}\right)(b-m) \\
\text { (ii) } 2 y_{2}-y_{1} \geqslant b\end{array}$ & $\left(y_{2}-y_{1}\right) \frac{\left(m-y_{1}\right)^{2}}{s^{2}+\left(m-y_{1}\right)^{2}}$ & $y_{1}, m+\frac{s^{2}}{m-y_{1}}$ \\
\hline $\begin{array}{l}2 y_{2}-b \leqslant m \leqslant b \\
0 \leqslant s^{2} \leqslant\left(m-2 y_{2}+b\right)(b-m)\end{array}$ & $\frac{1}{2}\left(y_{2}+m-2 y_{1}-s_{m y_{2}}\right)$ & $y_{2}-s_{m y_{2}}, y_{2}+s_{m y_{2}}$ \\
\hline $\begin{array}{l}2 y_{2}-b \leqslant m \leqslant b \\
\left(m-2 y_{2}+b\right)(b-m) \leqslant s^{2} \\
\quad \leqslant\left(m-y_{1}\right)(b-m)\end{array}$ & $y_{2}-y_{1}+\frac{s^{2}+\left(m-y_{2}\right)(m-b)}{s^{2}+(m-b)^{2}}(m-b)$ & $m-\frac{s^{2}}{b-m}, b$ \\
\hline $\begin{array}{l}y_{1} \leqslant m \leqslant 2 y_{2}-b \\
0 \leqslant s^{2} \leqslant\left(m-y_{1}\right)(b-m)\end{array}$ & $y_{2}-y_{1}+\frac{s^{2}+\left(m-y_{2}\right)(m-b)}{s^{2}+(m-b)^{2}}(m-b)$ & $m-\frac{s^{2}}{b-m}, b$ \\
\hline
\end{tabular}

\section{REFERENCES}

BowERS JR., N. L. (1969). An upper bound on the stop-loss net premium. Transactions of the Society of Actuaries, 21, 211-217.

DE VYLDER, F. (1982). Best upper bounds for integrals with respect to measures allowed to vary under conical and integral constraints. Insurance: Mathematics and Economics, 1 (2), 109-130.

De VyLDER, F. and GoovaERTS, M. (1982a). Upper and lower bounds on stop-loss premiums in case of known expectation and variance of the risk variable. Mitt. der Ver. schw. Vers. Math., 149-164.

DE VYLDER, F. and GoovaerTs, M. (1982b). Analytical best upper bounds for stop-loss premiums. Insurance: Mathematics and Economics, 1 (3), 197-211. 


\section{THE STATICS AND DYNAMICS OF INCOME}

ISBN 0-905028-03-1. 250 pages hardback Price $£ 14.00$ (U.S. \$30.00). April 1981

Edited by N. A. Klevmarken and J. A. Lybeck

Most work on the personal distribution of incomes has concerned the statics of income. Much interest has been devoted to the measurement of income inequality and to the welfare aspects of inequality. There has been relatively less work to explain the causes of inequality and the changes in inequality. There is a growing need for longitudinal data, which would permit analyses of the dynamics of income, i.e. explain how individuals move up and down the income distribution and how income changes can be explained by market-related activities, schooling, social background and other individual characteristics as well as by policy measures.

Papers by: N. S. Blomquist, J. Creedy, B. Gustafsson, P. E. Hart, A. Jonsson, N. A. Klevmarken, A. F. Shorrocks, L. Soderstrom, R. Spant, P. L. I. Vartia, V. O. Vartia.

Summary by: Sir Henry Phelps Brown.

\section{IETO LTD}

Bank House, 8a Hill Road, Clevedon, Avon BS21 7HH, England 